\title{
Visceral Ischemia Caused by Extra-Anatomical Bypass for Coral Reef Aorta
}

\author{
Masashi Kawabori \\ Division of Cardiac Surgery, Brigham and Women's Hospital, Harvard Medical School, Boston, MA, USA \\ Email: kawabori.masashi@gmail.com
}

Received 24 June 2015; accepted 24 July 2015; published 27 July 2015

Copyright (C) 2015 by author and Scientific Research Publishing Inc. This work is licensed under the Creative Commons Attribution International License (CC BY). http://creativecommons.org/licenses/by/4.0/

\section{(c) (i) Open Access}

\begin{abstract}
A 72-year-old woman was presented with intermittent claudication of bilateral lower extremities, refractory hypertension, and mild renal impairment. Computed tomographic angiography showed severe aortic stenosis caused by calcifications protruding into the aortic lumen proximal and distal to the visceral and renal branches, so-called coral reef aorta. An axillo-iliac bypass was performed. Postoperatively, the patient developed ileus and acute renal failure, presumably caused by a steal phenomenon to the lower extremities. Endovascular stenting of the aorta increased forward blood flow and dramatically improved the patient's condition. This case study illustrates potential hemodynamic complications after extra-anatomical axillo-iliac bypass for coral reef aorta.
\end{abstract}

\section{Keywords}

Coral Reef Aorta, Extra-Anatomical Bypass, Aortic Stenosis, Ischemia

\section{Introduction}

The term coral reef aorta (CRA) was first used by Qvarfordt et al. [1] to describe focal calcifications in the aorta. CRA occurs most commonly in the suprarenal abdominal aorta and less frequently in the infrarenal aorta [2] [3]. Calcifications can obstruct the aortic lumen, causing visceral ischemia, hypertension from decreased renal blood flow, heart failure, and ischemia of the lower extremities. We described a patient with coral reef aorta who developed visceral ischemia after extra-anatomical bypass for lower limb ischemia. The visceral ischemia was successfully treated by endovascular aortic stenting. 


\section{Case Report}

A 72-year-old woman was admitted to our hospital with intermittent claudication and hypertension refractory to medical treatment. She had no history of diabetes, dyslipidemia, abdominal surgery, visceral ischemia, or smoking. Upper limb blood pressure was 180/70 mmHg. The ankle-brachial index was decreased at 0.45 on the right and 0.43 on the left. Serum creatinine was elevated to $1.44 \mathrm{mg} / \mathrm{dl}$, and the estimated glomerular filtration rate was $28.19 \mathrm{ml} / \mathrm{min} / 1.73 \mathrm{~m}^{2}$. Computed tomographic angiography revealed calcification and thickening of the aortic wall from the distal thoracic to pararenal aorta, and a narrowed aortic lumen (Figure 1). Stenosis was severe just proximal to the origin of the superior mesenteric artery and less severe downstream of the renal arteries. The celiac artery was occluded. The patient was diagnosed with coral reef aorta causing decreased perfusion of the kidneys and lower extremities.

Anatomical repair was considered high risk for this patient. Therefore, we performed extra-anatomical bypass from the right axillaryartery to the right external iliac artery using a 10-mm ring-enforced ePTFE vascular graft (WL Gore \& Associates, Newark, DE, USA) (Figure 2). The patient's upper limb blood pressure was 127/65 mmHg after surgery. Her ankle-brachial index improved to 0.70 and 0.64 on the right and left side, respectively. On the second postoperative day, she developed ileus and acute renal failure, with a peak serum creatinine of $2.98 \mathrm{mg} / \mathrm{dl}$. The extra-anatomical bypass might have reduced the antegrade pressure driving blood to the visceral and renal arteries through the narrowed aorta after cardiac output was redistributed to the lower extremities. Endovascular repair was performed using an $8 \times 37-\mathrm{mm}$ balloon-expandable stent (Express LD; Boston Scientific, Marlborough, MA, USA) placed in the aorta proximal to the origin of the superior mesenteric artery (Figure 3). The aortic pressure gradient decreased from 60 to $20 \mathrm{mmHg}$. Dual antiplatelet therapy (aspirin and clopidogrel) was started, and she recovered from the ileus and acute renal failure. At the 2-year postoperative follow-up, she was well.

\section{Discussion}

Symptomatic CRA often has an unfavorable outcome. It compromises perfusion of the digestive system, kidneys, and lower extremities and increases the risk of cardiovascular and cerebral events secondary to hyperten-

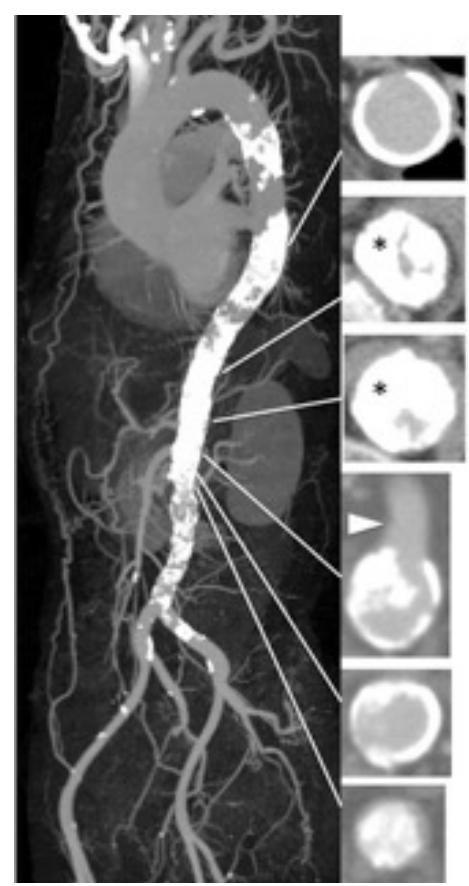

Figure 1. Preoperative computed tomographic angiography, showing prominent calcification (asterisks) proximal to the origin of the superior mesenteric artery (arrowhead). 


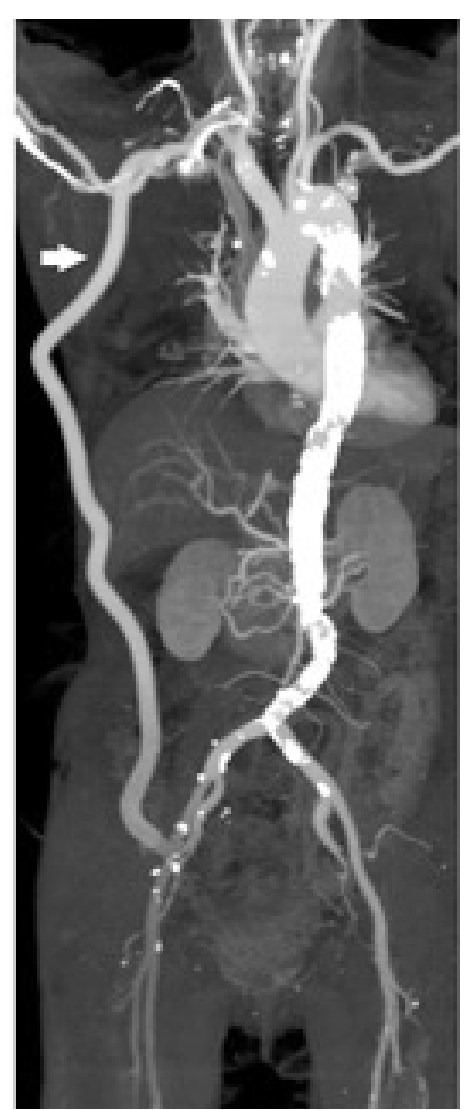

Figure 2. Postoperative computed tomographic angiography. An arrow indicates the bypass graft from the right axillary artery to the right external iliac artery.

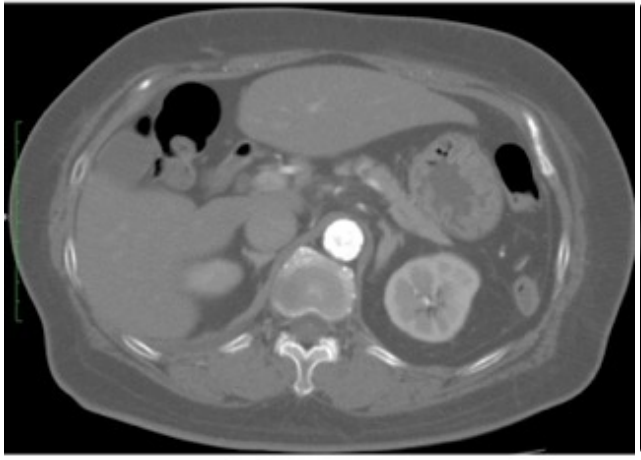

(a)

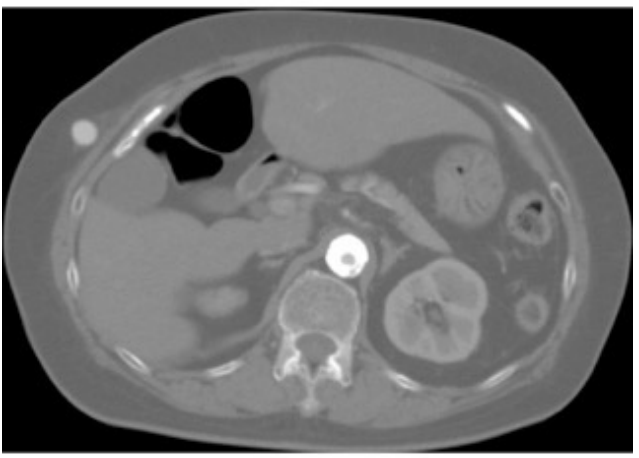

(b)

Figure 3. Computed tomographic angiography before (a) and after (b) endovascular repair.

sion [4]. Treatment options include surgical endarterectomy, aortic reconstruction, extra-anatomical bypass, and endovascular repair [5].

Anatomical repair results in hemodynamic improvement and long-term patency, but is a high-risk procedure with a reported 30 -day mortality of $8.7 \%$ and a rate of postoperative complications requiring corrective surgery of $13.9 \%$ [6]. Schulte et al. [7] reported that $29 \%$ of patients experienced complications related to vascular reconstruction, including occlusion of an accessory renal artery, the renal artery, superior mesenteric artery, or inferior mesenteric artery, with ischemia or infarction of the corresponding organs. 
Extra-anatomical bypass is a lower-risk treatment option for CRA [8]. It effectively restores blood supply to the lower extremities, and although long-term patency is not guaranteed, we consider this procedure is appropriate given the advanced age of this patient and the relatively high risk of anatomical repair. Ileus and anuria after the bypass was attributed to ischemia resulting from a steal phenomenon to the lower extremities. In our case, a bare stent was chosen because the lower profile might be beneficial in the severely calcified aorta. The patient's condition improved dramatically, but long-term patency of aortic stenting for CRA was uncertain and close follow-up was mandatory.

This case highlights the importance of thorough evaluation of stenotic lesions in coral reef aorta, and illustrates potential hemodynamic consequences of redirection of cardiac output to the lower body following extraanatomical bypass.

\section{References}

[1] Qvarfordt, P.G., Reilly, L.M., Sedwitz, M., Ehrenfeld, W.K. and Stoney, R.J. (1984) “Coral Reef” Atherosclerosis of the Suprarenal Aorta: A Unique Clinical Entity. Journal of Vascular Surgery, 1, 903-909. http://dx.doi.org/10.1016/0741-5214(84)90023-5

[2] Peillon, C., Morlet, C., Laissy, J.P., Watelet, J. and Testart, J. (1989) Endoaortic Calcific Proliferation of the Upper Abdominal Aorta. Annals of Vascular Surgery, 3, 181-186. http://dx.doi.org/10.1016/s0890-5096(06)62014-1

[3] Schulte, K.M., Reiher, L., Grabitz, L. and Sandmann, W. (2000) Coral Reef Aorta: A Long-Term Study of 21 Patients. Annals of Vascular Surgery, 14, 626-633. http://dx.doi.org/10.1007/s100169910091

[4] Minnee, R.C., Idu, M.M. and Balm, R. (2005) Coral Reef Aorta: Case Reports and Review of the Literature. European Journal of Vascular and Endovascular Surgery, 29, 557. http://dx.doi.org/10.1016/j.ejvs.2005.02.010

[5] Tapper, S.S., Edwards, W.H., Edwards Jr., W.H., Mulherin Jr., J.L. and Martin 3rd., R.S. (1993) Suprarenal Aortic Occlusion. Journal of Vascular Surgery, 18, 372-380. http://dx.doi.org/10.1016/0741-5214(93)90254-j

[6] Sagban, A.T., Grotemeyer, D., Rehbein, H., Sandmann, W., Duran, M., Balzer, K.M., et al. (2010) Occlusive Aortic Disease as Coral Reef Aorta-Experience in 80 Cases. Zentralblatt für Chirurgie, 135, 438-444. http://dx.doi.org/10.1055/s-0030-1247382

[7] Shulte, K., Reiher, L. and Sandmann, W. (2000) Coral Reef Aorta: A Long-Term Study of 21 Patients. Annals of Vascular Surgery, 14, 626-633. http://dx.doi.org/10.1007/s100169910091

[8] Ota, T., Okada, M., Koterazawa, T., Nishiwaki, M., Yamamoto, S., Ozawa, S., et al. (1990) Comparison of the Patency Rates of Dacron and PTFE Grafts for Axillofemoral Bypass Operations. Journal of Artificial Organs, 19, 1258-1261. 